\title{
Same day cancellation of elective ENT surgeries in a tertiary referral hospital
}

\author{
Ambalika Shakya, Urmila Gurung*, Rabindra B Pradhananga, Bijaya Kharel and Kripa Dongol \\ Department of ENT-Head and Neck Surgery, Tribhuvan University Teaching Hospital, Maharajgunj Medical Campus, Maharajgunj, Kathmandu, Bagmati \\ Province, Nepal
}

\begin{abstract}
Objective: Cancellations of elective surgical cases on the scheduled day in a tertiary referral hospital vary from $0.1 \%$ to $40 \%$ due to varied causes. Such cancellations result in financial loss, waste of resources of a health care facility with equally disappointing loss of time and money of the patients and the caretakers. The current study assesses the magnitude and causes of cancellation of cases on the same day of surgery in ENT department of a tertiary referral hospital and suggests measures to reduce the cancellation rate.

Research design and methodology: This is a retrospective study done in the Department of ENT-Head and Neck Surgery, Tribhuvan University Teaching Hospital. The age, sex, planned procedure, type of anaesthesia and the reasons for cancellation of patients listed for surgery from July 2019 to February 2020 were collected from the operation theatre register.

Results: Out of 1279 scheduled cases over a period of 7 months, 77 (6.02\%) got cancelled on the day of surgery of which $41(53.24 \%)$ were listed for procedure under general anaesthesia and remaining 36(46.76\%) were listed under local anaesthesia. The most common cause for cancellation was medical reason accounting for 44 $(57.14 \%)$ cases. Lack of operating time and patient factors accounted for $16 / 77$ (28.57\%) cancellations each whilst technical reason was the least common cause as seen in $1 / 77(1.29 \%)$ case.

Conclusion: The overall rate of cancellation on the day of surgery in ENT department is $6.02 \%$. This can be further reduced as most of the factors are preventable and amenable with vigilant preoperative evaluation of patients, efficient and judicious use of resources and proper planning of the operative list.
\end{abstract}

Abbreviations: ENT: Ear, Nose, Throat; GA: General anaesthesia; LA: Local anaesthesia

\section{Introduction}

Surgery is one of the main modalities of treatment in various ENT (Ear, Nose and Throat) diseases. A smooth functioning of any surgical facility requires a proper team of dedicated staffs, surgeons, anaesthesiologists, nurses, helpers, biomedical technicians in addition to a well-equipped operating $\operatorname{room}(\mathrm{s})$. Developed countries put in a lot of resources for proper functioning and maintenance of operating facilities including the necessary human resources.

Unfortunately, the condition is not the same in most of the developing countries. Resource limited settings definitely reduce the capacity of a facility giving rise to various problems, cancellations of routine cases being one of them [1,2]. After a hopeful wait of several days to months, unfortunate cancellations of surgical cases, that too on the day of surgery, take a toll not only on the health facility but the patients as well. Financial loss, waste of resources and time have a negative impact on the health care facility. Emotional trauma, loss of time and money are some of the problems suffered by patients which could lead to mistrust over the institution [3]. Causes of cancellation can be multifactorial and may vary amongst different hospitals [4]. The incidence of cancellations of elective surgical cases vary from $0.1 \%$ to $40 \%$ in various literature [1,2,5-8]. Literatures suggest decreasing cancellation rates by applying mitigating measures derived from previous studies [9] and in addition, an integrative review of cancellation of surgeries helps to understand the cause of the local problem prior to devising a proper solution suited to the local hospital setting [10].

The department has its share of cancellation of cases on the day of surgery. Detail study about the magnitude and factual reasons for cancellations are therefore important in our context for proper mitigation of the problems in future. However, no similar study till date has been published in the institution to determine the extent of the problem. Hence, the purpose of this study was to assess the magnitude of elective case cancellations on the day of surgery, seek the reasons behind such cancellations and suggest measures to reduce the cancellation rate.

\section{Materials and methods}

This is a retrospective study carried out in the Department of ENTHead and Neck Surgery, Tribhuvan University Teaching Hospital after taking the ethical approval from the institutional review board of Institute of Medicine. The age, sex, planned procedure, type of anaesthesia and the reasons for cancellation of patients listed for

${ }^{\star}$ Correspondence to: Urmila Gurung, Department of ENT-Head and Neck Surgery, Tribhuvan University Teaching Hospital, Maharajgunj Medical Campus, Maharajgunj, Kathmandu, Bagmati Province, Nepal, Tel: +9779841470057; E-mail: dr.urmila.gurung@gmail.com

Key words: elective surgical procedures, operative, surgery

Received: June 02, 2020; Accepted: June 19, 2020; Published: June 22, 2020 
surgery from July 2019 to February 2020 were collected from the operation theatre register.

The causes of cancellations were broadly classified into medical reasons, patient factors, lack of operating time and technical reasons. Cases cancelled due to various ailments in the patients like raised blood pressure, respiratory tract infections, coagulopathy, fever were categorized under medical factors. Patient not turning up during surgery, denying surgery just before the surgery began, turning up without performing proper investigations were kept under patient factors. Cancellations due to lack of operating time were grouped in a different list. Technical difficulties like unavailability of postoperative monitoring bed, malfunctioning of the operating table or surgical equipment like microscope, endoscope was also listed separately. Data was entered in an excel sheet (MS excel 2013). The descriptive data was analysed using mean, range, frequency, and percentages.

\section{Results}

A total 1279 cases were scheduled for elective surgical procedures during the seven months of study period. Out of 1279, 1202 (93.98\%) underwent the procedures. Total cancelled cases were $77(6.02 \%)$. Out of 77 cases, $41(53.24 \%)$ were listed for procedure under GA and remaining 36 (46.76\%) were listed under LA. The age ranged from 1-86 years, the mean being 38.58 ( $\mathrm{SD} \pm 19.59$ ). Females comprised of $35 / 77$ (45.45\%) patients whilst males were $42 / 77$ (54.55\%). The majority of causes of cancellation were related to medical reasons comprising of $44 / 77$ (57.14\%) cases whereas the least common cause was due to technical reason in $1 / 77(1.29 \%)$ case (Table 1$)$.

High blood pressure was the most common medical reason behind the cancellations especially in those scheduled under local anaesthesia. Various infections were the second common cause which also included a case each of chronic otitis media - mucosal type and pre-auricular sinus with ongoing infection. Interestingly, two cases listed under GA showed new ECG changes prior to induction (Table 1).

Sixteen cases listed under GA were cancelled due to lack of operating time. Another sixteen cases mostly posted under LA were cancelled due to patient factors such as patient not turning up on the day of surgery, patient refusing surgery, unavailability of reports of certain investigations and low pain threshold. Unavailability of an intensive care monitoring bed for a paediatric airway surgery case amounted to the single technical reason for cancellation (Table 1).

\section{Discussion and conclusion}

Last minute cancellation of surgical cases brings a great dissatisfaction amongst patients and their relatives and wastes a lot of resources of the health care facility. Attempts are made however to lower such incidence of late cancellations. In our study, the overall cancellation rate of surgery of routine elective cases was $6.02 \%$. The results are comparable to various studies [6,11-13]. Matzek et al. [14] had reported cancellation rate of $2 \%$ of all the vascular surgeries performed at Mayo Clinic, Rochester, Minnesota. In a tertiary hospital in Karachi, Pakistan, the rate of overall surgical case cancellation was $6.8 \%$ [13]. Kaddoum et al. [6] revealed $4.4 \%$ as the cancellation rate in a tertiary Lebanese hospital. Studies done at major Australian and American tertiary hospitals show an overall cancellation rate of $13.2 \%$ [7,15] with cancellation in ENT Department amounting to $19.6 \%$ [7]. Medical reasons were the commonest cause of cancellations in our study accounting for $57.14 \%$. Forty-seven percent of cases were cancelled due to medical factors in a study done by Lau et al. [8]. Chamisa et al. [16] reported $65.1 \%$ of cases getting cancelled due to medical reasons and ill patient preparation. Dimitriadis et al. [11] in his study based on a tertiary hospital in the U.K. showed medical factors to be the leading cause of case cancellation accounting for 33.13\%. Some studies had comparatively less amount of cancellations of $1 \%-15 \%$, due to medical factors [1-3].

Raised blood pressure (new onset or worsening of blood pressure of previously hypertensive) was one of the prominent reasons in our study. Further analysis showed a greater number of raised blood pressure in patients scheduled under local anaesthesia. Apprehension and anxiety resulting from the thought of having to go through the procedure could have spiked up the blood pressure [3]. Prescription of evening dose of anxiolytics may alleviate the symptoms, keeping in

Table 1. Causes of cancellation as per anaesthesia required for the procedure $(n=77)$

\begin{tabular}{|c|c|c|c|c|}
\hline Causes of cancellation & & $\begin{array}{l}\text { Number of patients } \\
\text { Posted under GA }\end{array}$ & $\begin{array}{l}\text { Number of patients posted under } \\
\text { LA }\end{array}$ & Total $(\%)(n=77)$ \\
\hline \multicolumn{4}{|l|}{ Medical reasons } & \multirow{14}{*}{ 44/77 (57.14) } \\
\hline High blood pressure & & 6 & 15 & \\
\hline \multirow{4}{*}{ Infections } & Upper respiratory Tract infection & 6 & 1 & \\
\hline & Infection at the site of surgery & 2 & & \\
\hline & Lower respiratory Tract infection & 1 & & \\
\hline & Urinary tract infection & 1 & & \\
\hline \multicolumn{2}{|l|}{ ECG changes } & 2 & & \\
\hline \multicolumn{2}{|l|}{ High blood sugar } & & 2 & \\
\hline \multicolumn{2}{|l|}{ Low platelet count } & & 2 & \\
\hline \multicolumn{2}{|l|}{ Fever } & 1 & 1 & \\
\hline \multicolumn{2}{|l|}{ Hemolytic anemia } & 1 & & \\
\hline \multicolumn{2}{|l|}{ Myopathy } & 1 & & \\
\hline \multicolumn{2}{|l|}{ Rabies vaccination } & & 1 & \\
\hline \multicolumn{2}{|l|}{ Tachycardia } & & 1 & \\
\hline \multicolumn{2}{|l|}{ Lack of operating time } & 16 & & $16 / 77(28.57)$ \\
\hline \multicolumn{5}{|l|}{ Patient factors } \\
\hline \multicolumn{2}{|l|}{ No show } & 2 & 9 & \multirow{4}{*}{$16 / 77(28.57)$} \\
\hline \multicolumn{2}{|l|}{ Refusal for surgery } & 1 & 1 & \\
\hline \multicolumn{2}{|l|}{ Incomplete lab reports } & & 1 & \\
\hline \multicolumn{2}{|l|}{ Low pain threshold } & & 2 & \\
\hline \multicolumn{2}{|l|}{ Technical reason } & 1 & & $1 / 77(1.29)$ \\
\hline
\end{tabular}


mind the side effects of light-headedness, fatigue, unsteadiness lasting up to 24 hours of administration [17].

Apparently, certain medical illnesses may be missed in pre-aesthetic clinic owing to the crowded, noisy environment which is preventable with proper administrative management [3].

This holds true in our setup also owing to the large number of patients being catered in the outpatient where we run simultaneous preoperative assessment of patients 3 to 7 days before surgery. Referrals to the respective specialties are made in case of chronic conditions and to the aesthetic department for GA cases only. Rai et al, in their study performed the assessment clinics 2 to 4 weeks prior to the booked date of surgery and were successful to confine the rate of same day cancellation of surgery to $5 \%$, which was estimated to be $9 \%$ without the intervention [18]. Hence, vigilant pre-anaesthetic check-ups two weeks before the surgery would likely detect any medical issues that could be corrected in time hence reducing the number of last minute cancellations of surgeries due to medical factors in our context as well.

Lack of operating time and patient related factors contributed equally to the case cancellations i.e. $16 \%$ each. Overscheduling of the operation list, previous cases overrunning due to unexpected complications or surgeries being performed by newer less experienced residents and surgeons might have well contributed to the cause. Many studies have shown lack of operating time as one of the major reasons for cancellations [1-3,5,11]. Delay in theatre time due to delay in shifting the patients in between surgeries, late arrival of surgeons or anaesthesiologists, unavailability of staffs as noted in various studies $[2,3,7]$ were not evident in our study. Overscheduling of cases in the operating list can be curbed to much extent. One of the solutions could be to calculate the mean operating time (from giving anaesthesia to shifting the patient out of the operating room) of the surgery and applying it for a realistic scheduling $[11,18]$.

Most of the patients not showing up on the day of procedure were from those allocated in day care surgeries under LA. Two daycare surgery cases were abandoned due to low pain threshold of the patients. Some patients were listed in the operation list on chance basis when booked patients became unfit for surgery. Such patients probably were not adequately prepared mentally towards the procedure resulting in their absence on the day of surgery. Inadequate counselling owing to noisy environment and overcrowding in the office might also have contributed to the cause as stated by Dimitradis et al. [11] also. Providing patient friendly pamphlets that accurately instruct the patients regarding the surgery is one solution in reducing no show on the day of surgery $[11,19]$.

Unavailability of an intensive care unit bed for an airway surgery led to cancellation of one of the cases of our department. In a developing country with limited resources, being a tertiary hospital and one of the highest referrals centre of the entire country, it is not uncommon to have shortage of monitoring bed during the time of dire needs. The beds may be unavailable on the first hand or pre-booked beds may get occupied due to serious emergency cases. Similar problems have been reported in various studies even in the developed countries $[4,11,20]$. Dimitriadis et al. [11] in their study write "ring fencing" of the beds prior to surgery at the cost of referring the needy ones to the nearby hospitals.

There are certain limitations to this study. Being a retrospective study, a few data could have been missed. Nonetheless, this study gives a baseline depiction of the status of same day cancellation of elective surgery in our department, from which identifiable causes can be rectified. A rolling audit in the future is recommended to assess reduction in the cancellation rates after implementing rectifiable measure.

To conclude, the overall rate of cancellation on the day of surgery in our department is $6.02 \%$. This can be further reduced as most of the factors are preventable and amenable with vigilant pre-operative evaluation of patients, efficient and judicious use of resources and proper planning of the operative list.

\section{Reference}

1. Garg R, Bhalotra AR, Bhadoria P, Gupta N, Anand, R. (2009) Reasons for cancellation of cases on the day of surgery-a prospective study. Indian J Anaesth 53: 35. [Crossref]

2. Chalya PL, Gilyoma JM, Mabula JB, Simbila S, Ngayomela IH, et al. (2011) Incidence, causes and pattern of cancellation of Elective surgical operations in a University Teaching Hospital in the Lake Zone, Tanzania. Afr Health Sci 11: 438-443. [Crossref]

3. Ganesan I, Anuradha R, Ravindrakumar P (2015) Audit of cancellation of elective surgeries in a teaching hospital in south India. J Evol Med Dent Sci 4: 5322-5328.

4. Sahraoui A, Elarref M (2014) Bed crisis and elective surgery late cancellations: an approach using the theory of constraints. Qatar Med J: 1-11. [Crossref]

5. Nanjappa BA, Kabeer KK, Smile SR (2014) Elective surgical case cancellation-an Audit. Int J of Cur Res Rev 6: 19.

6. Kaddoum R, Fadlallah R, Hitti E, Fadi, EJ, El Eid G (2016) Causes of cancellations on the day of surgery at a Tertiary Teaching Hospital. BMC Health Serv Res 16: 1-8. [Crossref]

7. Schofield WN, Rubin GL, Piza M, Lai YY, Sindhusake D, et al. (2005) Cancellation of operations on the day of intended surgery at a major Australian referral hospital. Med J Aust 182: 612-615. [Crossref]

8. Lau HK, Chen TH, Liou CM, Chou MC, Hung WT (2010) Retrospective analysis of surgery postponed or cancelled in the operating room. J Clin Anesth 22: 237-240. [Crossref]

9. Hovlid E, Bukve O, Haug K, Aslaksen AB, von Plessen C (2012) A new pathway for elective surgery to reduce cancellation rates. BMC Health Serv Res 12: 154. [Crossref]

10. Al Talalwah N, McIltrot KH (2019) Cancellation of surgeries: integrative review. $J$ Perianesth Nurs 34: 86-96. [Crossref]

11. Dimitriadis PA, Iyer S, Evgeniou E (2013) The challenge of cancellations on the day of surgery. Int J Surg 11: 1126-1130. [Crossref]

12. Hand R, Levin P, Stanziola A (1990) The causes of cancelled elective surgery. Qual Assur Util Rev 5: 2-6. [Crossref]

13. Monem A, Nadeem A, Khan FA (2019) Hypertension as a reason for cancellation of elective surgical cases on day of surgery: A five year audit report from The Aga Khan University Hospital Karachi. J Pak Med Assoc 69: 1860-1863. [Crossref]

14. Matzek LJ, Smith BB, Mauermann WJ, Bower TC, Smith MM (2020) Same-Day Cancellation in Vascular Surgery: 10-Year Review at a Large Tertiary Care Center. Ann Vasc Surg 62: 349-355. [Crossref]

15. Pollard JB, Olson L (1999) Early Outpatient Preoperative Anesthesia Assessment: Does It Help to Reduce Operating Room Cancellations? Anesth Analg 89: 502-505. [Crossref]

16. Chamisa I (2008) Why is surgery cancelled? A retrospective evaluation. S Afr J Surg 46: 79-81. [Crossref]

17. Carroll JK, Cullinan E, Clarke L, Davis NF (2012) The role of anxiolytic premedication in reducing preoperative anxiety. Br J Nurs 21: 479-483. [Crossref]

18. Rai MR, Pandit JJ (2003) Day of surgery cancellations after nurse-led pre-assessment in an elective surgical centre: the first 2 years. Anaesthesia 58: 692-699.

19. Basson MD, Butler TW, Verma H (2006) Predicting patient nonappearance for surgery as a scheduling strategy to optimize operating room utilization in a veterans' administration hospital. Anesthesiology 104: 826-834. [Crossref]

20. Griffin X, Griffin D, Berry A, Hunter D (2006) Cancellation of elective surgery - any improvement after ten years? Bull R Coll Surg Engl 88: 28-30.

Copyright: (C2020 Shakya A. This is an open-access article distributed under the terms of the Creative Commons Attribution License, which permits unrestricted use, distribution, and reproduction in any medium, provided the original author and source are credited. 